\title{
Composição química e de ácidos graxos do músculo longissimus dorsi e da gordura subcutânea de tourinhos Red Norte e Nelore
}

\author{
Leandro Sâmia Lopes ${ }^{1}$, Márcio Machado Ladeira ${ }^{1 *}$, Otávio Rodrigues Machado Neto ${ }^{1}$, Eduardo \\ Mendes Ramos ${ }^{2}$, Pedro Veiga Rodrigues Paulino ${ }^{3}$, Mário Luiz Chizzotti ${ }^{1^{*}}$, Mário César Guerreiro ${ }^{4}$
}

${ }^{1}$ Departamento de Zootecnia da Universidade Federal de Lavras.

2 Departamento de Ciências dos Alimentos da Universidade Federal de Lavras.

${ }^{3}$ Departamento de Zootecnia da Universidade Federal de Viçosa.

${ }^{4}$ Departamento de Química da Universidade Federal de Lavras.

* Pesquisador do CNPq e INCT - Ciência Animal.

RESUMO - Objetivou-se com este trabalho avaliar a composição química e o perfil de ácidos graxos do músculo longissimus dorsi e da gordura subcutânea de tourinhos Red Norte e Nelore terminados em confinamento. Utilizaram-se 44 animais, sendo 22 Red Norte com peso vivo inicial médio de $367 \pm 30 \mathrm{~kg}$ e 22 do grupo Nelore com peso vivo inicial médio de $361 \pm 30 \mathrm{~kg}$. Os animais receberam ração à vontade durante 112 dias e foram abatidos com 519 e 482 kg, respectivamente. Amostras do músculo longissimus dorsi e da gordura subcutânea foram coletadas 24 horas após abate entre a 12a e 13a costelas para análise da composição centesimal e do perfil de ácidos graxos. As análises de ácidos graxos foram realizadas por meio de cromatografia gasosa, em coluna capilar de $100 \mathrm{~m}$. Não houve diferença na composição química da carne entre os grupos genéticos. Nos animais Red Norte, foram maiores os teores dos ácidos graxos pentadecanoico, palmítico, palmitoleico, linoleico e ácido linoleico conjugado (CLA), enquanto nos animais Nelore foi encontrado o maior teor de ácido oleico. O músculo longissimus dorsi apresentou maiores teores dos ácidos láurico, heptadecenoico, esteárico, linoleico, $\alpha$-linolênico e araquidônico. Em comparação ao músculo longissimus dorsi, na gordura subcutânea foram maiores os teores dos ácidos mirístico, miristoleico, pentadecanoico, palmítico, palmitoleico, oleico e CLA. Os animais Red Norte apresentaram maiores teores de ácidos graxos saturados em comparação aos Nelore. Em bovinos, o perfil de ácidos graxos depositados no músculo é diferente do observado na gordura subcutânea. O perfil de ácidos graxos da carne de tourinhos difere entre grupos genéticos.

Palavras-chave: bovinos, CLA, lipídeos, saúde humana

\section{Chemical composition and of fatty acids of the muscle longissimus dorsi and backfat of Red Norte and young Nellore bulls}

\begin{abstract}
The objective of this study was to evaluate the chemical composition and the fatty acid profile of the longissimus dorsi muscle and the backfat thickness of Red Norte and Nellore young bulls finished in feedlot. Fourty-four animals (22 Red Norte with initial average weight of $367 \pm 30 \mathrm{~kg}$ and 22 Nellore at initial average weight of $361 \pm 30 \mathrm{~kg}$ ) were used. The animals were fed ad libitum during 112 days, slaughtered at 519 and $482 \mathrm{~kg}$, respectively. Samples of the longissimus dorsi muscle and backfat thickness were collected 24 hours after slaughter between the 12th and 13th ribs for analysis of the chemical composition and the fatty acids profile. Fatty acid analyses were performed by gas chromatography with a 100-m capillary column. There was no difference for the chemical composition of the meat between the genetic groups. Red Norte animals showed higher contents of pentadecanoic, palmitic, palmitoleic, linoleic and conjugated linoleic acid (CLA) fatty acids, while Nellore animals had the highest content of oleic acid. The muscle longissimus dorsi showed greater concentrations of lauric, heptadecenoic, stearic, linoleic, $\alpha$-linoleic and arachidonic acids. Comparing the fatty acid deposited in the longissimus dorsi muscle with backfat thickness, the latter showed higher contents of miristic, miristoleic, pentadecanoic, palmitic, palmitoleic, oleic and CLA acids. Red Norte animals showed higher contents of saturated fatty acid than Nellore. In bovine, the profile of fatty acids deposited in the muscle is different than the that in the backfat thickness. The fatty acids profile of the meat from young bulls differs between genetic groups.
\end{abstract}

Key Words: cattle, CLA, human health, lipids

Recebido em 17/12/2010 e aprovado em 7/7/2011 


\section{Introdução}

A carne bovina fornece nutrientes essenciais e de alto valor biológico, como proteínas, vitaminas, ácidos graxos essenciais e minerais, porém, nos últimos anos, tem sido associada ao surgimento de doenças cardiovasculares, devido às características de sua gordura, que apresenta maiores concentrações de ácidos graxos saturados (AGS) e menores concentrações de ácidos graxos monoinsaturados (AGMI) e poliinsaturados (AGPI) em comparação à gordura de não-ruminantes.

Essa diferença decorre principalmente do processo de biohidrogenação que ocorre no rúmen pela ação dos microrganismos. No entanto, as análises químicas da carne bovina sem gordura de cobertura apresentam teores de gordura inferiores a 5\%. É de interesse do consumidor que a carne bovina apresente menores teores de lipídeos totais e ácidos graxos saturados; e maiores teores de AGMI e AGPI, o que permitiria maior qualidade do alimento, prevenindo o desenvolvimento de doenças cardiovasculares. São três os fatores que podem interferir na composição de ácidos graxos da carne: a dieta utilizada, o grupo genético e a idade de abate do animal (Pires et al., 2008).

Além dos principais ácidos graxos insaturados (AGI) presentes na carne, outros, presentes em menores concentrações, surgem como participantes de processos benéficos à saúde humana. Entre eles, há o ácido linoleico conjugado (CLA), que apresenta funções como atividade anticarcinogênica, combate a diabetes e aterosclerose, entre outras (Moreira et al., 2003). Raças bovinas podem apresentar distintos padrões de deposição de tecido adiposo e perfil de ácidos graxos na carne, pois raças que apresentam maior tendência de deposição de ácidos graxos no músculo podem fornecer maior quantidade de CLA e AGPI na carne (Mir et al., 2004).

O grupo genético Red Norte é oriundo do cruzamento da raças Nelore, Red Angus, Senepol e Caracu. Isso significa a presença de genes de Bos indicus, Bos taurus britânico e Bos taurus continental, porém estudos sobre o Red Norte são escassos na literatura científica. Segundo Bressan et al. (2011), variações entre raças podem explicar 20 a 31\% da variação observada na atividade da enzima $\Delta^{9}$ dessaturase, enquanto o sistema de terminação pode explicar apenas de 2 a $8 \%$ desta variação.

Portanto, objetivou-se com este trabalho avaliar a composição química e o perfil de ácidos graxos da carne e da gordura subcutânea de tourinhos Red Norte e Nelore terminados em confinamento.

\section{Material e Métodos}

O experimento foi conduzido no Setor de Bovinocultura de Corte do Departamento de Zootecnia da Universidade Federal de Lavras no período de julho a outubro de 2007. Foram utilizados 44 tourinhos de dois grupos genéticos, sendo: 22 Nelore com peso vivo inicial médio de $361 \pm 31 \mathrm{~kg}$ e 22 Red Norte com peso vivo inicial médio de $367 \pm 30 \mathrm{~kg}$. Os animais pertenciam a um mesmo rebanho comercial e, anteriormente ao confinamento, estavam em pastagem de Brachiaria sp.

Os animais foram confinados em baias coletivas com área de $30 \mathrm{~m}^{2}$ por animal, sendo separados em duas baias, de acordo com o grupo genético. A instalação de confinamento continha piso de terra compactado, área próxima ao comedouro em concreto e divisórias feitas de arame liso. Os bebedouros coletivos localizavam-se na divisória das duas baias e o comedouro utilizado era do tipo vinilona, disposto transversalmente na parte superior do curralete, $\mathrm{com} 70 \mathrm{~cm}$ lineares para cada animal.

O período de confinamento foi composto de 28 dias de adaptação à dieta e 84 dias de período experimental. No início do confinamento, os animais foram tratados contra ecto e endoparasitos. A dieta foi balanceada para atender às exigências de ganho de $1,4 \mathrm{~kg} / \mathrm{dia}$, de acordo com o National Research Council (NRC, 2000) (Tabela 1), sendo fornecida à vontade em forma de ração completa às $8 \mathrm{~h}$ e às $15 \mathrm{~h}$.

Um dia antes de serem levados para o frigorífico, os animais foram pesados após jejum de sólidos de 16 horas.

Tabela 1 - Composição de ingredientes e bromatológica da dieta experimental

\begin{tabular}{|c|c|}
\hline Ingredientes & Composição (\%MS) \\
\hline Silagem de milho & 50,0 \\
\hline Milho integral moído & 23,0 \\
\hline Polpa cítrica & 11,5 \\
\hline Farelo de soja & 10,0 \\
\hline Farelo de algodão & 3,4 \\
\hline Ureia & 0,5 \\
\hline Núcleo mineral* & 1,6 \\
\hline \multicolumn{2}{|l|}{ Nutrientes } \\
\hline Matéria seca ${ }^{1}$ & 47,7 \\
\hline Proteína bruta ${ }^{2}$ & 14,3 \\
\hline Fibra em detergente neutro ${ }^{2}$ & 30,1 \\
\hline Carboidratos não-fibrosos² & 47,9 \\
\hline Extrato etéreo ${ }^{2}$ & 3,0 \\
\hline Nutrientes digestíveis totais 2,3 & 70,3 \\
\hline \multicolumn{2}{|c|}{$\begin{array}{l}\text { * Ca: } 235 \text { g; P: } 45 \text { g; S: } 23 \text { g; Na: } 80.18 \text { g; Zn: } 2.38 \text { mg; Cu: } 625 \text { mg; Fe: } 1.18 \text { mg } \\
\text { Mn: } 312 \text { mg: Co: } 32 \mathrm{mg} \text {;: } 41.6 \text { mg; Se: } 11.25 \text { mg; vit. A: } 70.000 \text { UI; vit. D3 } \\
\text { 5.000 UI; vit. E: } 15 \text { UI; niacin: } 3.33 \mathrm{mg} \\
\text { 1 Base da matéria natural. } \\
2 \text { Base da matéria seca. } \\
{ }^{3} \text { Calculado segundo o NRC (2001). }\end{array}$} \\
\hline
\end{tabular}


Após a pesagem, foram realimentados e transportados para um frigorífico industrial, distante $60 \mathrm{~km}$. No frigorífico, durante o manejo pré-abate, os animais foram submetidos a jejum e dieta hídrica por 24 horas em currais sem cobertura. O abate foi realizado de acordo com as normais oficiais do RIISPOA (Brasil, 1997), em que os animais foram insensibilizados pelo método da concussão cerebral (pistola pneumática), seguindo-se de sangria, remoção do couro e evisceração.

A composição centesimal foi determinada em amostras do músculo longissimus dorsi coletadas entre a $12^{\mathrm{a}}$ e a $13^{\mathrm{a}}$ costelas, após 24 horas de resfriamento da carcaça e armazenadas em freezer com temperatura de $-20{ }^{\circ} \mathrm{C}$. Dessas amostras, foi retirada a gordura subcutânea, que, posteriormente, foi colocada em multiprocessador para obtenção de uma massa homogênea. A PB foi quantificada pelo método de Kjeldahl, o EE foi extraído pelo método de Soxhlet, a umidade em estufa a $105^{\circ} \mathrm{C}$ por 24 horas e a matéria mineral (MM) em mufla a $550^{\circ} \mathrm{C}$ (Silva \& Queiroz, 2002).

Para análise do perfil de ácidos graxos, foram retiradas outra amostra do músculo longissimus dorsi e uma amostra de gordura subcutânea (entre a $12^{\mathrm{a}}$ e a $13^{\underline{a}}$ costelas), que foram armazenadas a $-20^{\circ} \mathrm{C}$. As amostras de longissimus dorsi foram descongeladas à temperatura de refrigeração $\left(5^{\circ} \mathrm{C}\right)$ durante 12 horas e submetidas à limpeza para retirada da gordura subcutânea e extração de lipídeos. A extração dos ácidos graxos foi determinada segundo metodologia de Folch et al. (1957).

A determinação do perfil de ácidos graxos seguiu os procedimentos estabelecidos por Hartman \& Lago (1973). Uma amostra de $5 \mathrm{~mL}$ do extrato lipídico foi concentrada em banho-maria a $45^{\circ} \mathrm{C}$, com nitrogênio gasoso, procedendo-se à saponificação com solução de hidróxido de sódio em metanol 0,5 M, seguida de metilação com cloreto de amônia, metanol e ácido sulfúrico. Após a metilação, 5 mL de hexano foram adicionados e agitados por 10 segundos para separação dos ácidos graxos esterificados. Em seguida, $3 \mathrm{~mL}$ da porção sobrenadante (hexano e ácidos graxos metilados) foram retirados e concentrados novamente em banho-maria a $45{ }^{\circ} \mathrm{C}$, com nitrogênio gasoso. No ato da injeção, esse extrato foi diluído com $1 \mathrm{~mL}$ de hexano e $1 \mu \mathrm{L}$ dessa solução foi injetado em cromatógrafo a gás com detector de ionização de chama (Shimadzu, CG-2010) equipado com coluna capilar de dimensões: $100 \mathrm{~m} \times 0,25 \mathrm{~mm} \times 0,20 \mu \mathrm{m}$ (SuplecoSP2560).

As condições cromatográficas foram: temperatura inicial da coluna de $140^{\circ} \mathrm{C}$ por 5 minutos e elevação de $4^{\circ} \mathrm{C} /$ minuto até $240{ }^{\circ} \mathrm{C}$; após, $240{ }^{\circ} \mathrm{C}$, manutenção por 30 minutos. A temperatura do injetor e do detector foi mantida a $260{ }^{\circ} \mathrm{C}$.
Os ácidos graxos foram identificados por comparação com os tempos de retenção apresentados pelo padrão cromatográfico de C4:0 a C24:0 (Supelco ${ }^{\mathrm{TM}} 37$ Componente FAME Mix, 100 mg Neat). As concentrações dos ácidos graxos foram determinadas pelas áreas de pico apresentadas no cromatograma para cada ácido em relação à área total dos ácidos graxos. Os dados foram expressos como porcentagem da área de cada ácido graxo.

As atividades das enzimas $\Delta^{9}$ dessaturases e elongase foram determinadas, de acordo com Malau-Aduli et al. (1997), Kazala et al.(1999)e Pitchford et al.(2002), por meio deíndices matemáticos. O índice de aterogenicidade foi calculado conforme a proposta de Ulbricht \& Southgate (1991), como indicador para o risco de doença cardiovascular. Os cálculos foram feitos da seguinte forma:

$\Delta^{9}$ dessaturase $16: 100[(\mathrm{C} 16: 1$ cis9)/(C16 :1cis9 + $\mathrm{C} 16: 0)]$

$\Delta{ }^{9}$ dessaturase $18: 100[(\mathrm{C} 18: 1$ cis 9$) /(\mathrm{C} 18: 1$ cis $9+$

C18:0)]

Elongase : $100[(\mathrm{C} 18: 0+\mathrm{C} 18: 1$ cis9)/

(C16 :0+C16 :1cis9+C18:0+C18 :1cis9)]

Aterogenicidade: [C12:0+4(C14:0)+C16:0]/( AGS + $\sum$ AGP $)$

A composição química e o perfil de ácidos graxos foram submetidos à análise de variância, usando o software SAS (Statistical Analyses System, versão 9.1), utilizando-se um modelo misto com medidas repetidas no espaço com os efeitos fixos de grupo genético, local de deposição de gordura e interação grupo genético × local de deposição de gordura e os efeitos aleatórios de animal. O efeito do local de deposição de gordura foi considerado como repetido no espaço utilizando a opção “Repeated”, em relação a animal. Diversas estruturas de covariância dos erros foram ajustadas e a tipo "Un" foi selecionada por apresentar o menor valor do critério de informação Bayesiano (BIC). Os graus de liberdade foram ajustados usando a opção Kenward-Roger. A significância foi declarada a $\mathrm{P} \leq 0.05$.

\section{Resultados e Discussão}

Não houve diferença na composição química do músculo dos animais Red Norte e Nelore (Tabela 2). A semelhança

Tabela 2 - Médias e erros-padrão da média (EPM) da composição centesimal (\%) do músculo longissimus dorsi de tourinhos Red Norte e Nelore

\begin{tabular}{lcccc}
\hline & Red Norte & Nelore & EPM & $P$ \\
\hline Umidade & 74,6 & 74,2 & 0,18 & 0,12 \\
Proteína & 21,1 & 21,9 & 0,43 & 0,21 \\
Cinzas & 1,0 & 1,0 & 0,01 & 0,80 \\
Gordura & 2,1 & 2,3 & 0,19 & 0,52 \\
\hline
\end{tabular}

R. Bras. Zootec., v.41, n.4, p.978-985, 2012 
entre os resultados de umidade, proteína, cinzas e gordura pode estar relacionada ao fato de o sistema de terminação, a dieta e a classe sexual dos animais estudados terem sido iguais.

Os níveis de proteína na carne são praticamente constantes, enquanto os de umidade e gordura apresentam correlação negativa, ou seja, quando o teor gordura é mais elevado, a umidade é menor e vice-versa. Com exceção da gordura, existe pequena diferença na composição química para a mesma espécie animal e o mesmo músculo estudado (Abrahão et al., 2008).

Independentemente do grupo genético avaliado e do local de deposição de gordura, os ácidos graxos encontrados em maiores concentrações foram o oleico, o palmítico e o esteárico (Tabela 3), que representam aproximadamente $80 \%$ do total de ácidos. A concentração de ácido oleico corresponde à metade desta proporção. Esses ácidos tem função hipocolesterolêmica, já que atuam elevando o HDL plasmático.

Houve interação grupo genético $\times$ local de deposição de ácidos graxos apenas para os ácidos palmítico, palmitoleico e oleico.

A biossíntese de gordura pelo animal, na qual são formados principalmente os ácidos graxos C16:0, C18:0 e C18:1, pode ser uma explicação para as maiores concentrações de ácido oleico nos animais da raça Nelore. Este grupo genético apresentou no último período de confinamento queda acentuada no ganho de peso vivo, o que permite inferir que estavam próximos do peso à maturidade e, consequentemente, apresentavam maior síntese de lipídeos. Esta afirmação ajuda a explicar, também, a maior concentração de ácido linoleico encontrada nos animais Red Norte, pois a menor síntese endógena de ácidos graxos permitiria obter maior concentração deste ácido, obtido apenas pela dieta.

Animais Bos indicus podem apresentar maiores concentrações de ácido mirístico e menores concentrações de ácido palmítico, em relação a animais Bos taurus e seus cruzamentos (St. John et al., 1991; Huerta-Leidenz, 1993). Todavia, neste estudo foram encontradas maiores concentrações apenas para o ácido palmítico nos animais Red Norte, já que os teores de ácido mirístico foram semelhantes.

Os maiores valores de CLA obtidos nos animais Red Norte (1,08 vs 0,96\%) permitem inferir que o grupo genético influencia a deposição de CLA na carne, o que pode ocorrer caso haja diferenças na atividade da enzima $\Delta^{9}$ dessaturase, que é responsável pela transformação do ácido vaccênico em CLA nos tecidos (Griinari \& Bauman, 1999). A velocidade de escape ruminal dos ácidos graxos parcialmente biohidrogenados também pode ser um fator que influencia os teores de CLA na carne.

Resultados semelhantes foram encontrados por Menezes et al. (2009), que relataram maior atividade da enzima $\Delta{ }^{9}$ dessaturase em animais mestiços Bos indicus $\times$ Bos taurus em comparação a animais zebuínos puros.

As altas concentrações de CLA encontradas neste experimento podem ser justificadas pela dieta experimental, pois a alta quantidade de amido, aliada a níveis elevados de silagem de milho, favorece o desenvolvimento da população de bactérias e protozoários. De acordo com Jenkins et al. (2008), os protozoários apresentam maiores concentrações de AGI que as bactérias, sendo fonte importante de AGPI e CLA para ser incorporados na carne. Os autores relataram que os valores de CLA encontrados nos protozoários foram 3 a 8 vezes maiores que os registrados nas bactérias.

Tabela 3 - Médias das concentrações e erros-padrão médios (EPM) dos ácidos graxos no músculo longissimus dorsi na gordura subcutânea (\%) e nas carnes de tourinhos Red Norte e Nelore

\begin{tabular}{|c|c|c|c|c|c|c|c|c|c|}
\hline Ácido graxo & & Red Norte & Nelore & E P M & $P$ & Músculo & Subcutânea & EPM & $P$ \\
\hline Láurico & C12:0 & 0,07 & 0,08 & 0,003 & $<0,01$ & 0,09 & 0,07 & 0,003 & $<0,01$ \\
\hline Mirístico & C14:0 & 3,03 & 2,92 & 0,08 & 0,16 & 2,67 & 3,29 & 0,08 & $<0,01$ \\
\hline Miristoleico & C14:1 & 0,95 & 0,99 & 0,05 & 0,73 & 0,75 & 1,19 & 0,05 & $<0,01$ \\
\hline Pentadecanoico & C15:0 & 0,36 & 0,33 & 0,009 & $<0,01$ & 0,33 & 0,37 & 0,009 & $<0,01$ \\
\hline Palmítico* & C16:0 & 25,4 & 23,6 & 0,38 & 0,02 & 22,8 & 26,3 & 0,38 & $<0,01$ \\
\hline Palmitoleico* & C16:1 & 3,59 & 3,26 & 0,10 & 0,02 & 2,83 & 4,02 & 0,10 & $<0,01$ \\
\hline Margárico & C17:0 & 0,97 & 0,98 & 0,02 & 0,49 & 0,97 & 0,98 & 0,02 & 0,03 \\
\hline Heptadecenoico & C17:1 & 1,17 & 1,11 & 0,05 & 0,62 & 1,45 & 0,83 & 0,05 & $<0,01$ \\
\hline Esteárico & C18:0 & 16,9 & 16,0 & 0,46 & 0,63 & 17,1 & 15,8 & 0,46 & 0,11 \\
\hline Oleico* & C18:1 & 38,2 & 42,2 & 0,97 & $<0,01$ & 38,7 & 41,6 & 0,97 & 0,10 \\
\hline Vaccênico** & C18:1 t11 & 2,96 & 2,82 & 0,09 & 0,17 & - & - & - & - \\
\hline Linoleico & C18:2 & 2,82 & 2,43 & 0,12 & 0,04 & 3,81 & 1,44 & 0,12 & $<0,01$ \\
\hline$\alpha$-linolênico & C18:3 & 0,30 & 0,28 & 0,02 & 0,51 & 0,43 & 0,16 & 0,02 & $<0,01$ \\
\hline CLA & C18:2 c9- t11 & 1,08 & 0,96 & 0,04 & 0,04 & 0,94 & 1,10 & 0,04 & 0,01 \\
\hline Araquidônico & C20:4 & 0,07 & 0,08 & 0,02 & 0,16 & 0,12 & 0,02 & 0,02 & $<0,01$ \\
\hline
\end{tabular}

* Interação entre grupo genético e local de deposição de ácidos graxos $(\mathrm{P}<0,05)$.

** Ácido graxo quantificado apenas no músculo longissumus dorsi. 
Com os maiores valores de ácido vaccênico, em relação aos valores do ácido C18:2 cis9 trans11, sugere-se que os primeiros passos da biohidrogenação ruminal ocorrem mais rapidamente que a conversão de ácido vaccênico em esteárico. Portanto, o ácido vaccênico se acumula no rúmen e se torna mais disponível para absorção após sua chegada ao intestino (Kazama et al., 2008).

Ao avaliar o local de deposição de gordura, verificou-se que o músculo apresentou maiores concentrações dos ácidos linoleico e $\alpha$-linolênico, que não apresentam capacidade hipercolesterolêmica. Esses ácidos graxos não influenciam os níveis de LDL plasmáticos no ser humano. De acordo com Menezes et al. (2009), os ácidos ácidos linoleico e $\alpha$-linolênico tem efeito benéfico, pois são precursores de hormônios eicosanoides e fazem parte dos fosfolipídios da membrana.

Os maiores teores encontrados para os ácidos linoleico e $\alpha$-linolênico no músculo, em relação à gordura subcutânea, podem ser justificados pela maior ação das enzimas que atuam na síntese de lipídeos no tecido adiposo. Dessa forma, a maior síntese endógena de ácidos graxos na gordura subcutânea, principalmente de ácido oleico, contribuiria para menor concentração dos ácidos linoleico e $\alpha$-linolênico neste tecido.

A gordura subcutânea apresentou maior concentração de ácido oleico e CLA. De acordo com Knight et al. (2003), a enzima $\Delta^{9}$ dessaturase é mais ativa no tecido adiposo, o que poderia justificar os maiores teores de CLA e oleico. Apesar das diferenças significativas $(\mathrm{P}<0,04)$ nas concentrações destes ácidos graxos nos tecidos, estes foram 17,0 e 7,5\% maiores no tecido adiposo.

As interações local de deposição de gordura $\times$ grupo genético ocorreram porque as concentrações destes ácidos só foram influenciadas quando a deposição ocorreu na gordura subcutânea. Isto comprova que o perfil de ácidos graxos no músculo sofre menor alteração (Tabela 4).

Oliveira et al. (2011) também encontraram menor alteração na concentração de ácidos graxos no músculo em relação à gordura subcutânea. Neste caso, os autores utilizaram diferentes dietas, porém com animais do mesmo grupo genético.

A concentração dos ácidos graxos palmítico e palmitoleico na gordura subcutânea foi maior nos animais Red Norte. Por outro lado, a gordura subcutânea dos animais Nelore apresentou maior concentração de ácido oleico.

O produto final da lipogênese nos tecidos animais é, geralmente, o ácido palmítico, embora este ácido constitua apenas 20 a 30\% do total de ácidos graxos presentes na carne (Rule et al., 1995). Uma possível explicação para os maiores e menores valores dos ácidos graxos oleico e palmítico, respectivamente, na gordura subcutânea dos animais Nelore poderia ser em virtude da maior transformação do ácido palmítico em oleico por meio dos processos de elongação e dessaturação.

Outra possível explicação para o maior teor de ácido palmitoleico encontrado na gordura subcutânea dos animais

Tabela 4 - Médias das concentrações e erros-padrão médios (EPM) dos ácidos graxos no músculo longissimus dorsi e na gordura subcutânea da carne de tourinhos Red Norte e Nelore

\begin{tabular}{|c|c|c|c|c|c|c|c|c|c|}
\hline \multirow[b]{2}{*}{ Ácido graxo } & & \multicolumn{4}{|c|}{ Músculo } & \multicolumn{4}{|c|}{ Subcutânea } \\
\hline & & Red Norte & Nelore & EPM & $P$ & Red Norte & Nelore & EPM & $P$ \\
\hline Palmítico & C16:0 & 22,9 & 22,7 & 0,53 & 0,52 & 28,0 & 24,6 & 0,53 & $<0,01$ \\
\hline Oleico & C18:1 & 38,2 & 39,3 & 1,38 & 0,62 & 38,2 & 45,1 & 1,35 & $<0,01$ \\
\hline
\end{tabular}

Tabela 5 - Médias e erros-padrão médios (EPM) do somatório e razões dos ácidos graxos no músculo, na gordura subcutânea e na carne de tourinhos Red Norte e Nelore

\begin{tabular}{|c|c|c|c|c|c|c|c|c|}
\hline Ácido graxo & Red Norte & Nelore & EPM & $P$ & Músculo & Subcutânea & EPM & $P$ \\
\hline$\sum$ saturados* & 47,7 & 44,9 & 0,74 & 0,04 & 45,1 & 47,3 & 0,74 & 0,01 \\
\hline$\sum$ insaturados & 52,3 & 55,1 & 0,79 & 0,04 & 54,9 & 52,7 & 0,79 & 0,03 \\
\hline$\sum$ monoinsaturados & 46,7 & 49,8 & 0,94 & 0,01 & 47,9 & 48,8 & 0,94 & 0,73 \\
\hline$\sum$ poliinsaturados & 5,6 & 4,7 & 0,26 & 0,26 & 7,0 & 3,9 & 0,26 & $<0,01$ \\
\hline Insat/Sat & 1,1 & 1,2 & 0,04 & 0,03 & 1,2 & 1,1 & 0,04 & 0,03 \\
\hline Ômega 3 & 0,58 & 0,52 & 0,04 & 0,61 & 0,89 & 0,22 & 0,04 & $<0,01$ \\
\hline Ômega 6 & 4,5 & 4,2 & 0,23 & 0,21 & 5,83 & 2,82 & 0,23 & $<0,01$ \\
\hline Ômega 6/ômega3 & 10,2 & 10,1 & 0,36 & 0,37 & 7,15 & 13,17 & 0,36 & $<0,01$ \\
\hline
\end{tabular}

* Interação grupo genético $\times$ local de deposição de ácidos graxos $(\mathrm{P}<0,05)$. 
Red Norte seria maior atividade da enzima $\Delta^{9}$ dessaturase 16, que é a responsável pela transformação de ácido palmítico em palmitoleico. Considerando o perfil de ácidos graxos apresentado, pode-se inferir que a gordura subcutânea dos animais Nelore, em relação à dos Red Norte, apresentou perfil de ácidos graxos mais saudáveis, já que poderia promover aumento no HDL e diminuição do LDL sanguíneo.

Os animais Red Norte apresentaram maior concentração de ácidos graxos saturados e menores teores de ácidos graxos insaturados e monoinsaturados em relação aos animais Nelore (Tabela 5). A gordura intramuscular apresentou maiores concentrações de ácidos graxos poliinsaturados, ácidos da série ômega 3 e 6 e maior relação AGI/AGS, enquanto a gordura subcutânea apresentou maior teor de ácidos graxos saturados e maior relação ômega6/ ômega3.

A diferença encontrada nos teores de AGS e AGI entre as raças está de acordo com informações de Huerta-Leidnenz et al. (1993) de que animais Bos indicus apresentam perfil de ácidos graxos no tecido adiposo menos saturado em relação ao de animais taurinos e seus cruzamentos.

De acordo com Di Marco et al. (2007), há predomínio de AGI na carne bovina, que ficou evidenciado no experimento, tanto na gordura subcutânea (52,7\%) quanto na gordura intramuscular (54,9\%). Uma possível explicação para a maior concentração de AGI pode ser a dieta contendo 50\% de concentrado, que contribui para a redução do pH ruminal, diminuindo a biohidrogenação e favorecendo a absorção de ácidos graxos insaturados no pós-rúmen. As maiores taxas de passagem de dietas utilizadas em confinamento também podem aumentar o escape de AGI do rúmen (Jenkins et al., 2008).

O maior teor de ácidos graxos monoinsaturados na carne dos animais Nelore pode ser, em parte, explicada pela maior concentração de ácido oleico na gordura subcutânea dos animais Nelore. Todavia, entre os diferentes depósitos de gordura, não houve diferença na concentração dos ácidos graxos monoinsaturados.

Houve interação grupo genético $\times$ local de deposição dos ácidos graxos saturados. Os grupos genéticos não diferiram entre si quanto à concentração de ácidos graxos saturados no músculo, porém os animais Red Norte apresentaram maior concentração $(49,6 \%)$ na gordura subcutânea em relação aos nelores $(45,1 \%)$, o que pode estar relacionado às diferenças nas concentrações dos ácidos palmítico, palmitoleico e oleico.

O músculo, além de menor teor de ácidos graxos saturados, apresentou também maiores teores dos ácidos da série ômega 3 e 6 , que são essenciais ao homem, pois o organismo não tem capacidade de sintetizá-los. Entretanto, a relação ômega 6/ômega 3, de ambos os depósitos, estão acima do proposto pelo Department of Health (1994), cuja relação não deve ser superior a 4:1, pois o consumo excessivo de ácidos da série ômega 6 pode levar ao desenvolvimento de algumas doenças degenerativas, como câncer, diabetes e artrite.

Ressalta-se que a carne é apenas um dos ingredientes da dieta humana e que não se deve levar em consideração apenas o seu conteúdo de triglicerídeos e, sim, o conteúdo total na dieta consumida. O consumo de carne bovina deve ser incentivado, uma vez que contém ácidos graxos benéficos à saúde humana, como o ácido oleico e o CLA. Este último é encontrado apenas em produtos de origem animal, principalmente ruminantes.

A maioria dos consumidores desconhece muitas informações importantes sobre o valor nutritivo da carne bovina, pois o consumo de carnes, especialmente vermelha, é recomendado para evitar riscos de câncer, síndromes metabólicas e obesidade (Biesalski, 2005). Resultados semelhantes aos teores de ácidos graxos saturados deste experimento foram encontrados por Laborde (2001) em animais Angus (47,3\%); Dinh (2006), em animais Angus (45,1\%); e Rodrigues et al. (2008), em Nelore (42,1\%). Huerta-Leidenz et al. (1996) observaram maiores teores de AGMI e menores de AGS (53,0 e 43,7\%, respectivamente) em animais da raça Brahman em relação aos da raça Hereford (51,4\% de AGMI e 45,6\% de AGS).

Houve diferença apenas para o índice de elongase entre os grupos genéticos estudados, sendo que no grupo Nelore a atividade desta enzima foi maior (Tabela 6). Os animais Nelore apresentaram também tendência $(\mathrm{P}=0,07)$ de superioridade para a atividade da enzima $\Delta^{9}$ dessaturase 18. A atividade da enzima $\Delta^{9}$ dessaturase 16 e o índice de aterogenicidade foram maiores na gordura subcutâna, enquanto no músculo foi maior a atividade da elongase (Tabela 6).

Os animais Nelore apresentaram maior concentração de ácido oleico (42,2\%) em comparação aos Red Norte (38,2\%). O índice de atividade da enzima $\Delta^{9}$ dessaturase 18 é calculado por um modelo matemático que leva em consideração os teores de ácido oleico no tecido. Como anteriormente comentado, os animais Red Norte foram abatidos antes de atingir o peso à maturidade, o que proporcionaria menor síntese do ácido graxo oleico no tecido adiposo, devido à menor atividade desta enzima.

Apesar de os animais Red Norte terem apresentado maiores concentrações de ácido palmitoleico, não houve diferença na estimativa da atividade da enzima $\Delta^{9}$ dessaturase 16. A maior quantidade de palmitoleico nos 
Tabela 6 - Médias e erros-padrão médios (EPM) dos índices de dessaturases e índice de aterogenicidade no músculo, na gordura subcutânea e na carne de tourinhos Red Norte e Nelore

\begin{tabular}{|c|c|c|c|c|c|c|c|c|}
\hline Índice & Red Norte & Nelore & EPM & $P$ & Músculo & Subcutânea & EPM & $P$ \\
\hline$\Delta^{9}$ dessaturase $16^{\mathrm{a}}$ & 12,5 & 12,6 & 0,26 & 0,58 & 11,2 & 13,9 & 0,26 & $<0,01$ \\
\hline$\Delta^{9}$ dessaturase $18^{b}$ & 69,6 & 72,1 & 1,05 & 0,07 & 70,3 & 71,5 & 1,02 & 0,22 \\
\hline Elongase $\mathrm{C}^{\mathrm{C} *}$ & 66,1 & 68,5 & 0,55 & $<0,01$ & 69,0 & 65,6 & 0,55 & $<0,01$ \\
\hline Aterogenicidade $^{\mathrm{d}}$ & 0,71 & 0,72 & 0,01 & 0,95 & 0,65 & 0,78 & 0,01 & $<0,01$ \\
\hline
\end{tabular}

* Interação grupo genético $\times$ local de deposição de ácidos graxos $(\mathrm{P}<0,05)$.

a $\Delta^{9}$ dessaturase $16: 100$ [(C16:1cis9)/(C16 :1cis9 + C16:0)].

b $\Delta^{9}$ dessaturase $18: 100$ [(C18:1cis9)/(C18:1cis9 + C18:0)].

c Elongase: 100 [(C18: 0 + C18: 1cis9)/(C16:0 + C16:1cis9 + C18:0 + C18:1cis9)].

d Aterogenicidade: [C12: $0+$ 4(14:0) + C16: 0]/"AGS + “AGPI).

animais Red Norte pode estar relacionada ao fato de que neste grupo genético havia maior concentração de palmítico.

Este resultado contrasta com o que foi descrito por Rossato et al. (2010) de que houve diferença na atividade da $\Delta^{9}$ dessaturase 16 para animais de diferentes grupos genéticos (Simental, Holandês, 1/2 Pardo-Suíço 1/2 Nelore, Tabapuã e Gir). Os animais Bos taurus apresentaram maior atividade $(11,5)$ em relação aos animais Bos indicus e o cruzamento (9,3). Todavia, Archibeque et al. (2005) alegam que o uso desses índices deve ser avaliado com cautela, pois a atividade das enzimas dessaturases, baseadas na concentração de ácidos graxos, não reflete a real atividade das enzimas nos tecidos.

A maior atividade da elongase, encontrada nos animais Nelore, pode ser explicada pelos menores valores de ácido palmítico e palmitoleico e maior teor de ácido oleico encontrado neste grupo genético. Este resultado comprova que o grupo Nelore estaria realizando maior biossíntese de ácido graxo, principalmente oleico.

De acordo com Smith (1995), a elongase tem maior atividade no tecido adiposo que no muscular, o que não ficou evidenciado neste trabalho. Os maiores valores encontrados nos índices de aterogenicidade da gordura subcutânea, em relação ao músculo, ocorreu principalmente porque esta gordura apresenta maiores concentrações dos ácidos graxos láurico, mirístico, palmítico e menor concentração de AGPI.

Embora a gordura subcutânea apresente maior valor de aterogenicidade, é importante ressaltar que, do seu total, aproximadamente $70 \%$ estão na forma de ácido estérico, AGMI e AGPI, não constituindo, assim, fonte de gordura potencialmente causadora de doenças cardiovasculares no homem. Além disso, o ácido oleico é o ácido graxo encontrado em maior quantidade e apresenta capacidade de elevação dos níveis de HDL sanguíneo.

Houve interação grupo genético $\times$ depósito de gordura para a atividade da enzima e elongase. Os animais Nelore apresentaram maior atividade dessa enzima $(67,9)$, em relação aos animais Red Norte $(63,3)$ na gordura subcutânea, o que ajuda a explicar os maiores valores de ácido oleico neste tecido. Todavia, a atividade da elongase no músculo não foi diferente entre os grupos genéticos.

\section{Conclusões}

A composição química da carne não foi influenciada pelos grupos genéticos. Há diferença no perfil de ácidos graxos depositados no músculo longissimus dorsi e na gordura subcutânea de bovinos, sendo que o primeiro tecido se apresenta mais favorável à saúde humana. Há influência do grupo genético sobre o perfil de ácidos graxos, pois a carne de animais Nelore apresenta maiores concentrações de ácidos graxos insaturados e monoinsaturados se comparada à de Red Norte. Animais Red Norte tem maior concentração de CLA, que se deposita mais na gordura subcutânea.

\section{Referências}

ABRAHÃO, J.J.S.; MARQUES, J.A.; MACEDO, L.M. et al. Composição química e perfil de ácidos graxos do músculo Longissimus de diferentes grupos genéticos terminados em confinamento. Acta Scientiarum Animal Science, v.30, n.4, p.443-449, 2008.

ARCHIBEQUE, S.L.; LUNT, D.K.; GILBERT, C.D. et al. Fatty acid indices of stearoyl-Coa dessaturase do not reflect actual stearoyl-Coa dessaturase enzyme activities in adipose tissues of beef steers finished with corn-, flaxssed-, or sorghum-based diets. Journal of Animal Science, v.83, p.1153-1166, 2005.

BIESALSKI, H.K. Meat as a component of a healthy diet - are there risks or benefits if meat is avoided in the diet? Meat Science, v.70, p.509-524, 2005.

BRASIL. Decreto n. 30,691, alterado pelos Decretos n. 1,255 de 2506-62, n. 1236 de 02-09-94, n. 1.812 de 08-02-96 e n. 2.244 de 04-06-97. Aprova o regulamento da inspeção industrial e sanitária de produtos de origem animal (RIISPOA). Lex: Diário Oficial da União de 5 de julho de 1997, seção I, p.11555. Brasília, 1997.

BRESSAN, M.C.; ROSSATO, L.V.; RODRIGUES, E.C. et al. Genotype $\mathrm{x}$ environment interactions for fatty acid profiles in Bos indicus and Bos taurus finished on pasture or with grain. Journal of Animal Science, v.89, n.1, p.221-232, 2011. 
DEPARTMENT OF HEALTH. Nutritional aspects of cardiovascular disease. London: HMSO, 1994. 178p. (Report on Health and Social Subjects, 46).

DI MARCO, O.N.; BARCELOS, J.O.; COSTA, E.C. Crescimento de bovinos de corte. Porto Alegre: NESPRO, 2007. 276p.

DINH, T.T.N. Lipid and cholesterol composition of the longissimus muscle from Angus, Brahman, and Romosinuano. 2006. 153f. Thesis (Master in Animal and Food Science) - Texas Tech University, Texas.

FOLCH, J.; LEES, M.; SLOANE-STANLEY, G.H. A simple method for the isolation and purification of total lipids from animal tissue. Journal of Biological Chemistry, v.226, n.1, p.497-509, 1957.

GRIINARI, J.M.; BAUMAN, D.E. Biosynthesis of conjugated linoleic acid and its incorporation into meat and milk in ruminants. In: YURAWECZ, M.P.; MOSSOBA, M.M.; KRAMER, J.K.G. (Eds.) Advances in conjugated linoleic research. Champaign: AOCS, 1999. v.1, p.180-200.

HARTMAN, N.L.; LAGO, R.C. A rapid preparation of fatty acid methyl esters from lipids. Laboratory Practice, v.22, n.9, p.475-476, 1973.

HUERTA-LEIDENZ, R.O.; CROSS, H.R.; SAVELL, J.W. et al. Comparison of the fatty acid composition of subcutaneous adipose tissue from mature Brahman and Hereford cows. Journal of Animal Science, v.71, p.625-630, 1993.

HUERTA-LEIDENZ, R.O.; CROSS, H.R.; SAVELL, J.W. et al. Fatty acid composition of subcutaneous adipose tissue from male calves at different stages of growth. Journal of Animal Science, v.74, p.1256-1264, 1996

JENKINS, T.C.; WALLACE, R.J.; MOATE, P.J. et al. Recent advances in biohydrogenation of unsatured fatty acids within the rumen microbial ecosystem. Journal of Animal Science, v.86, p.397-412, 2008.

KAZALA, E.C.; LOZEMAN, F.J.; MIR, P.S. et al. Relationship of fatty acid composition to intramuscular fat content in beef from crossbred Wagyu cattle. Journal of Animal Science, v.77, p.1717-1725, 1999.

KAZAMA, R.; ZEOULA, L.M.; PRADO, I.N. et al. Características quantitativas e qualitativas da carcaça de novilhas alimentadas com diferentes fontes energéticas em dietas à base de cascas de algodão e soja.. Revista Brasileira de Zootecnia, v.37, n.2, p.350-357, 2008.

KNIGHT, T.W.; KNOWLES, S.; DEATH, A.F. Factors affecting the variation in fatty acid concentrations in lean beef from grassfed cattle in New Zeland and implications for human health. New Zeland of Agricultural Research, v.46, p.83-95, 2003.

LABORDE, F.L.; MANDELL, I.B.; TOSH, J.J. et al. Breed effects on growth performance, carcass characteristics, fatty acid composition, and palatability attributes in finishing steers. Journal Animal Science, v.79, p.355-365, 2001.

MALAU-ADULI, A.E.O.; SIEBERT, B.D.; BOTTEMA, C.D.K. et al. A comparison of the fatty acid composition of triacylglycerols in adipose tissue from Limousin and Jersey cattle. Australian Journal Agricultural Research, v.48, p.715-722, 1997.
MENEZES, F.L.G.; RESTLE, J.; BRONDANI, I.L. et al. Perfil de ácidos graxos na carne de novilhos Charolês e Nelore puros e de gerações avançadas do cruzamento rotativo, terminados em confinamento. Ciência Rural, v.39, p.2478-2484, 2009.

MIR, P.S.; MACLLISTER, T.A.; SCOTT, S. et al. Conjugated linoleic acid-enriched beef production. American Journal Clinical Nurition, v.79, n.6, p.1207-1211, 2004.

MOREIRA, F.B.; SOUZA, N.E.; MATSUSHITA, M. et al. Evaluation of carcass characteristics and meat chemical composition of Bos indicus and Bos indicus x Bos taurus crossbred steers finished in pasture systems. Brazilian Archives of Biology and Technology, v.46, p.607-614, 2003.

NATIONAL RESEARCH COUNCIL - NRC. Nutrients requeriments of beef cattle. 7.ed. Washington, D.C.: National Academy of Sciences, 2000. 244p

NATIONAL RESEARCH COUNCIL - NRC. Nutrient requeriments of dairy cattle. 7.rev.ed. Washington, D.C.: National Academy of Sciences, 2001. 381p.

OLIVEIRA, D.M.; LADEIRA, M.M.; CHIZZOTTI, M.L. et al. Fatty acid profile and quantitative characteristics of meat from Zebu steers fed with different oilseeds. Journal of Animal Science, v.89, n.8, p.2546-2555, 2011.

PIRES, I.S.C.; ROSADO, G.P.; COSTA, N.M.B. et al. Composição centesimal e perfil de ácidos graxos da carne de novilho precoce alimentado com lipídeos protegidos. Ciência e Tecnologia de Alimentos, v.28, p.178-183, 2008 (supl.).

PITCHFORD, W.S.; DELAND, M.P.B.; SIEBERT, B.D. et al. Genetic variation in fatness and fatty acid composition of crossbred cattle. Journal Animal Science, v.80, p.2825-2832, 2002.

RODRIGUES, E.; ARRIGONI, M.B.; JORGE, A.M. et al. Características físicas e químicas da carne de novilhas de diferentes grupos genéticos no modelo biológico superprecoce. Revista Brasileira de Saúde e Produção Animal, v.9, n.3, p.594-604, 2008.

ROSSATO, L.V.; BRESSAN, M.C.; RODRIGUES, E.C. et al. Parâmetros físico-químicos e perfil de ácidos graxos da carne de bovinos Angus e Nelore terminados em pastagem. Revista Brasileira de Zootecnia, v.39, n.5, p.1127-1134, 2010.

RULE, D.C.; SMITH, S.B.; ROMANS, J.R. Fatty acids composition of muscle and adipose tissue of meat animals. In: SMITH, S.B.; SMITH, D.R. (Eds.). The biology of fat in meat animals Champaign: American Society of Animal Science, 1995. p.144-165.

SILVA, D.J.; QUEIROZ, A.C. Análise de alimentos: métodos químicos e biológicos. 3.ed. Viçosa, MG: UFV, 2002. 235p.

SMITH, S.B. Substrate utilization in ruminant adipose tissue. In: SMITH, S.B.; SMITH, D.R. (Eds.). The biology of fat in meat animals. Champaign: American Society of Animal Science, 1995. p.166-188.

ST. JOHN, L.C.; LUNT, D.K.; SMITH, S.B. Fatty acid elongation and desaturation enzyme Activities of bovine liver and subcutaneous adipose tissue microsomes. Journal of Animal Science, v.69, p.1064-1073, 1991.

ULBRICHT, T.L.V.; SOUTHGATE, D.A.T. Coronary heart disease: seven dietary factors. Lancet, v.338, n.8773, p.985-992, 1991. 